\title{
Rotation Effects of Potato, Maize, and Winter Wheat on Soil Erosion by Water
}

\author{
P. Fiener* \\ Dep. of Geography, Hydrogeography \\ and Climatology Research Group \\ Universität zu Köln \\ Albertus Magnus Platz \\ D-50923 Cologne \\ Germany
}

\section{K. Auerswald}

Lehrstuhl für Grünlandlehre

Technische Universität München

Am Hochanger 1

D-85350 Freising-Weihenstephan

Germany

\begin{abstract}
The effects of cultivating different crops or applying different management practices on water erosion have been widely evaluated in plot or field experiments. While these experiments have focused on the direct effects of a certain crop, there is comparably little information on how crops influence soil loss during the following years. Our objectives were to evaluate the extent to which water erosion differs between potato (Solanum tuberosum L.) and maize (Zea mays L.), and how these crops influence soil loss of a following winter wheat (Triticum aestivum L.) crop. Soil erosion was measured in four small neighboring watersheds $(0.8-4.2$ ha in size) during 198 rainfall-runoff events (1994-2001). Each watershed included one field with a crop rotation of winter wheat, potato, winter wheat, and maize. This rotation was shifted by $1 \mathrm{yr}$ for each field, and hence a comparison between the fields as well as a comparison over two crop rotations was possible. Runoff and soil loss from potato and maize differed only slightly because the better protection by cover during maize years was compensated by a better protection by contouring with potato ridges. Both effects were adequately described by the cover management and support practice (C and P) factors of the Revised Universal Soil Loss Equation. A clear difference in soil loss depending on the preceding crop occurred in the succeeding winter wheat fields. Especially in October, November, and February, soil loss after the potato crop was significantly higher. This could be explained by little residue cover, disintegration of large aggregates, and low stability of small aggregates following the potato crop. Carryover effects should be taken into account, optimizing crop rotations with respect to soil conservation. Moreover, they are highly relevant for modeling of water erosion from agricultural areas.
\end{abstract}

Abbreviations: RFR, roughness index; RUSLE, Revised Universal Soil Loss Equation; USLE, Universal Soil Loss Equation.
This article is dedicated to Udo Schwertmann on the occasion of his 80th birthday. He implemented the USLE for use in central Europe and inspired the longterm measuring program leading to this study.

Coil erosion is regarded as one of the most serious problems in $\checkmark$ agricultural soil use (Auerswald and Kutilek, 1998; Morgan, 1996). Besides field layout, soil loss can be influenced by the selection of crops and cultivation techniques. Hence, an enormous number of publications exist where different crops and cropping techniques have been compared. For statistical and practical reasons, these experiments are often performed on rather small plots, sometimes only a few square meters in size (Wischmeier and Smith, 1978; Lal, 1998; Quinton and Catt, 2004; Hill and Peart, 1998). It is questionable whether such results also apply to large areas, like fields or watersheds, where the transport capacity may be considerably higher than on small plots. Small plots are even more poorly suited to the case of crops grown on ridges perpendicular to the slope because the small amount of runoff rarely exceeds the storage capacity of the furrows between the ridges or causes a breakdown of the ridges, while both may be the case on larger fields. Hence there is a clear demand for experiments on larger fields or small watersheds comparing ridged and unridged crops grown along or across the slope (Foster, 2005).

In most cases, only the year is considered in which a certain crop is grown when comparing the erosion potential of different crops. Row crops like maize, potato, or soybean [Glycine max (L.) Merr.] are considered to be crops of high erosion potential unless grown with conservation techniques like reduced tillage, while small grain crops are mostly considered to be less prone to erosion. Carryover effects influencing soil loss during the following year are included in long-term experiments with monocultures, while they are rarely examined in crop rotations. In particular, the amount of crop residues availably for cover in the following year and soil aggregation may vary considerably depending on the preceding crop and will thus be a property that has to be assigned to the preceding crop. Especially preceding crops in no-till systems for small grain cereals have received little attention (Rasmussen, 1999).

We evaluated the hypothesis that soil loss during wheat depends on the preceding crop (maize vs. potato) and we analyzed, at a watershed scale, the direct effects of these crops with special emphasis on the influence of roughness height (flat vs. ridged) and orientation (across and along) on soil loss. 


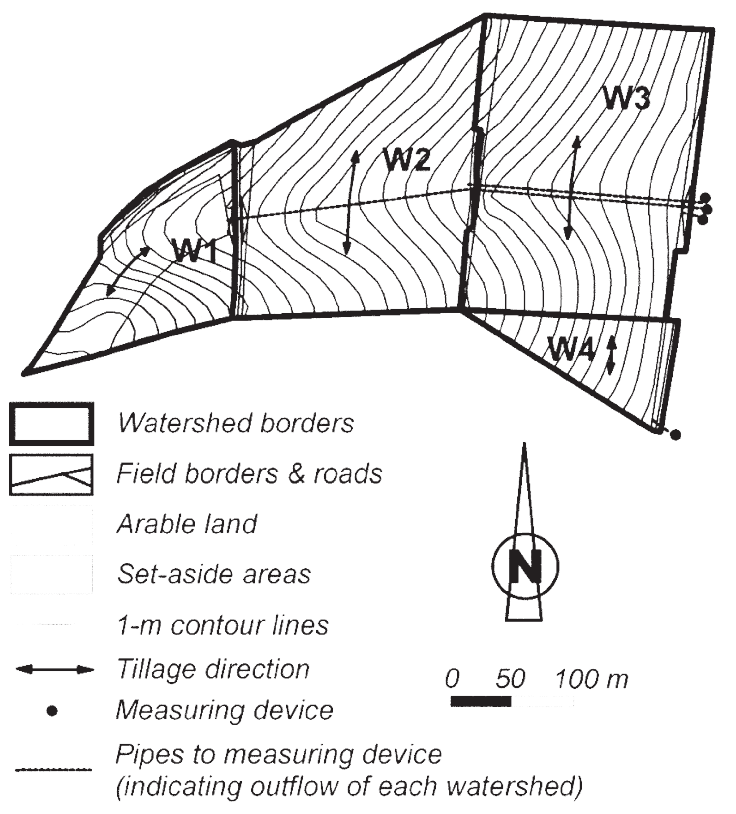

Fig. 1. Watershed topography, field borders, tillage direction, and location of measuring devices.

\section{Study Site and Cropping Practice}

The study site was part of the Scheyern Experimental Farm located about $40 \mathrm{~km}$ north of Munich in the Tertiary hills, an important agricultural landscape in central Europe. The study site covered four small adjacent agricultural watersheds (W1-W4) with a size of 0.8 to $4.2 \mathrm{ha}$ (Fig. 1), situated at an altitude of 458 to $478 \mathrm{~m}$ above sea level $\left(48^{\circ} 30^{\prime} 50^{\prime \prime} \mathrm{N}, 11^{\circ} 26^{\prime} 30^{\prime \prime} \mathrm{E}\right)$. Loamy or silty loamy Inceptisols predominated in all watersheds (Sinowski and Auerswald, 1999). During 1994 to 2001 , the mean annual air temperature was $8.4^{\circ} \mathrm{C}$ and the average annual precipitation was $834 \mathrm{~mm}$.

Each watershed included one field with some set-aside areas (field margins, hedges) and farm roads (Table 1). All fields were cropped with a rotation consisting of potato, winter wheat, maize, and winter wheat. The crop rotation was implemented in autumn 1992 after 1 yr (1992) of spring barley (Hordeum vulgare L.) and 1 yr of winter wheat (1991) on all fields to create similar starting conditions. Before that, all fields were part of one large field and were mainly farmed with small grain crops without

Table 1. Morphology, land use, slope, soil texture, and soil erodibility represented by the $K$ factor of the Universal Soil Loss Equation (USLE) for Watersheds W1 to W4.

\begin{tabular}{|c|c|c|c|c|}
\hline Parameter & W1 & W2 & W3 & W4 \\
\hline \multicolumn{5}{|l|}{ Morphology } \\
\hline Size, ha & 1.6 & 3.6 & 4.2 & 0.8 \\
\hline Mean slope, $\%$ & 7.4 & 6.9 & 7.3 & 7.5 \\
\hline \multicolumn{5}{|l|}{ Land use } \\
\hline Arable land, $\%$ & 53.1 & 94.9 & 92.9 & 90.3 \\
\hline Set-aside areas, \% & 44.6 & 3.4 & 6.6 & 5.6 \\
\hline Field roads, $\%$ & 2.4 & 1.7 & 0.6 & 4.1 \\
\hline \multicolumn{5}{|l|}{ Soil texture } \\
\hline Clay, $\mathrm{kg} \mathrm{kg}^{-1}$ & 0.17 & 0.22 & 0.21 & 0.19 \\
\hline Silt, $\mathrm{kg} \mathrm{kg}^{-1}$ & 0.38 & 0.47 & 0.58 & 0.56 \\
\hline Sand, $\mathrm{kg} \mathrm{kg}^{-1}$ & 0.45 & 0.31 & 0.21 & 0.25 \\
\hline Soil erodibility (K factor) & 0.32 & 0.43 & 0.49 & 0.49 \\
\hline
\end{tabular}

additional soil conservation measures. The measuring period started $2 \mathrm{yr}$ after the implementation of the rotation and extended from January 1994 to December 2001, covering $8 \mathrm{yr}$ and two full rotations.

The crop rotation was shifted by $1 \mathrm{yr}$ for each field to have every crop in every year (Table 2). Hence, a comparison between the fields and a comparison between crops was possible. On average, winter wheat was planted at the end of October and harvested in mid-August. After winter wheat harvest, a cover crop (mustard, Sinapis alba L.) was cultivated before each row crop. Potato ridges were already formed before mustard seeding and potato and maize were planted directly into the winter-frost-killed mustard, maintaining some mustard cover also after planting potato. Potato was planted at the end of April and harvested in early October, while maize was planted about $1 \mathrm{wk}$ later and harvested $2 \mathrm{wk}$ later than potato. Wide, low-pressure tires were used on all machinery to reduce soil compaction and to avoid the development of wheel-track depressions, which usually encourage runoff (Auerswald et al., 2000; Fiener and Auerswald, 2003a).

In general, the tillage direction was perpendicular to the main slope, except for Watershed W1, which had an unsuitable layout (Fig. 1). Large deviations from the contour can be found within each field, however, due to the undulating terrain and the rectangular field shape necessary for effective field management.

\section{MATERIALS AND METHODS Measuring Runoff and Sediment Delivery}

Runoff was collected at the lowest points of the watersheds where field borders were built to form small dams. From the dams, runoff was transmitted via underground tile outlets to the measuring systems. The measuring systems were based on a Coshocton-type wheel runoff sampler collecting an aliquot of about $0.5 \%$ from the total runoff coming from the outflow pipes. The aliquot volume was measured and at least one sample was taken during or after each event, which was later dried at $105^{\circ} \mathrm{C}$ to determine the sediment concentration.

During the first $2 \mathrm{yr}$ of the measuring campaign, the runoff aliquot was collected in $1-\mathrm{m}^{3}$ tanks, in which a $10-\mathrm{L}$ bucket was hanging to collect small events $\left(<2-\mathrm{m}^{3}\right.$ runoff) and the coarse sediment of large events. The coarse sediment was dried completely, while the fine sediment was agitated by a submersible pump (maximum flow $200 \mathrm{~L}$ $\mathrm{min}^{-1}$ ) for some minutes and then an aliquot was taken from the outflow of the pump. In later years, tipping buckets (volume $\sim 85 \mathrm{~mL}$ ) were installed at the outlets of the sampling wheels, which were connected to Isco 3700 portable samplers (Teledyne Isco, Lincoln, NE) that counted the number of tips and, after a defined runoff volume, automatically collected a sample from the undisturbed runoff before it flowed over the Coshocton-type wheel. Both methods avoided errors in sediment concentration introduced by collection tanks, which are difficult to homogenize before aliquot sampling (Ciesiolka et al., 2006). All measuring systems were tested for function at the end of each runoff event. A more detailed description of the measuring systems and the results of a precision test can be found in Fiener and Auerswald (2003b).

\section{Evaluating Soil Characteristics, Soil Cover, and Management Effects}

To evaluate the reasons for differences in soil loss and to determine the effects of potato and maize on the following winter wheat crop, we monitored (i) soil characteristics, namely aggregate size and aggregate stability, (ii) soil cover, (iii) surface roughness, and (iv) management effects. Less variability relative to soil erosion events can be expected for these parameters because only a little interaction with rainfall occurs. Therefore, the variability of these parameters was determined with a high temporal 
and spatial resolution for a shorter period than the erosion measurements, which reflected the full $8 \mathrm{yr}$.

During and after the cultivation of potato and maize, the different aggregate properties were measured up to 10 times at five different locations within the watersheds between 1993 and 1995. The top $3 \mathrm{~cm}$ of soil was carefully sampled to avoid aggregate stress and disintegration. The soil was air dried and sieved into fractions 8 to 5,5 to 2,2 to 1 , and $<1 \mathrm{~mm}$, and the median diameter was calculated from these fractions. Aggregate density was measured with 10 replications for the 8 - to $5-\mathrm{mm}$ aggregates according to Becher et al. (1990). Water drop penetration time (Bisdom et al., 1993) was measured for 0.03-g drops of deionized water imbibed by 108 - to 5 -mm aggregates. Aggregate density, size distribution, and water drop penetration were measured for only a subset of samples. Aggregate stability was determined for 1- to 2-mm aggregates with the percolation test (Auerswald, 1995), which measures the flow of deionized water through a column of $10 \mathrm{~g}$ of initially dry aggregates for $10 \mathrm{~min}$. Water flow is sensible to aggregate breakdown during fast wetting. To account for differences in soil texture of sampling locations, the percolation rates were corrected for differences in sand content using the equation of Mbagwu and Auerswald (1999).

Soil roughness under winter wheat after potato and maize was evaluated in two typical fields located in Watersheds W1 and W3 between October 1994 and May 1995. The chain method (Saleh, 1993) was used, where a 1-m-long chain with 5-mm links was placed on the soil surface, and the distance between the two ends of the chain was measured. Due to the measuring direction perpendicular to the tillage direction, the measurements represent random and tillage roughness for the winter wheat fields, which were cultivated using identical procedures after both preceding crops. In total, 14 measuring campaigns (total $n=74$ ) after potato and eight campaigns after maize (total $n=41$ ) were performed. From these measurements, the roughness index (RFR) of EUROSEM (Morgan et al., 1998) was calculated, defined by the shortest distance between two points on the ground $(X)$ and the total distance measured along the soil surface $(Y)$, which can easily be converted into random roughness (Jester and Klik, 2005):

$$
\mathrm{RFR}=\frac{Y-X}{Y} 100
$$

Plant and residue cover were measured biweekly during the vegetation period, every four weeks in autumn and spring, and before and after each soil management operation. The measurements were performed at three locations in each field between January 1993 and April 1997. Residue cover was measured along a pocket rule, while plant cover was determined from photographs taken from a height of up to $4 \mathrm{~m}$ (in the case of full-grown maize) using picture analysis and plant height measured with a pocket rule in the field.

For a direct comparison of the soil loss from potato and maize in the four watersheds, the combined effect of soil cover and management, especially the direction of tillage and hence of potato ridges, were taken into account by applying the CP factor of the Revised Universal Soil Loss Equation (RUSLE, Renard et al., 1996), which is the most appropri- ate model to be used with long-term averages. The RUSLE is based on the Universal Soil Loss Equation (USLE, Wischmeier and Smith, 1960), which has been extensively validated in this landscape (e.g., Schwertmann et al., 1987). The $C$ factor was calculated from the seasonal variation in three subfactors quantifying prior land use, mulch cover, and crop cover and the seasonal variation in rain erosivity. The crop cover subfactor (including tall weeds) was calculated from plant height and plant cover according to Wischmeier and Smith (1978), which is identical to the method for the RUSLE equation (Yoder et al., 1997). The mulch cover (including stones and small weeds growing close to the surface) was considered according to the equation by Kainz (1989), which was developed from rainfall simulator experiments performed in a neighboring region and under similar cropping conditions. The prior land use subfactor was set to 0.8 following the recommendations of Wischmeier (1975). This value agreed well with many results from rainfall simulator experiments under seedbed conditions on the research farm (Schröder and Auerswald, 2000) and the surrounding landscape (summarized in Schwertmann et al., 1987). The seasonal variation of rain erosivity is called the erosion index (Wischmeier, 1959) and is the ratio between the erosivity within a certain period and the annual erosivity. We report a daily erosion index expressed as a percentage per day. A constant value of $0.27 \% \mathrm{~d}^{-1}$ would denote a lack of any seasonality. To smooth the large fluctuations between individual days, a linearly weighted moving average $(t \pm 30 \mathrm{~d})$ was calculated. The same procedure was used to smooth the average seasonal distribution of precipitation.

The P factor depends on the crops' specific roughness, the tillage orientation relative to the local slope, the slope gradient, and the upslope drainage area. The parameters of orientation, gradient, and drainage area were derived from a detailed geodetic survey (Warren et al., 2004). It was resolved in a cascading triangular irregular network (Flacke et al., 1990) of 3424 triangles with a mean size of $31.4 \mathrm{~m}^{2}$ and the $P$ factor was then calculated for each triangle according to its individual topographic parameters (Kagerer and Auerswald, 1997) and, finally, the area-weighted P factors of all triangles within a watershed were combined to yield the overall $\mathrm{P}$ factor.

\section{RESULTS AND DISCUSSION Direct Effects}

During the observation period (1994-2001), on average, 198 rainfall-runoff events were measured per watershed. Focusing on the vegetation period (May-August), 1.48 events per month occurred, on average, during the 16 watershed years 

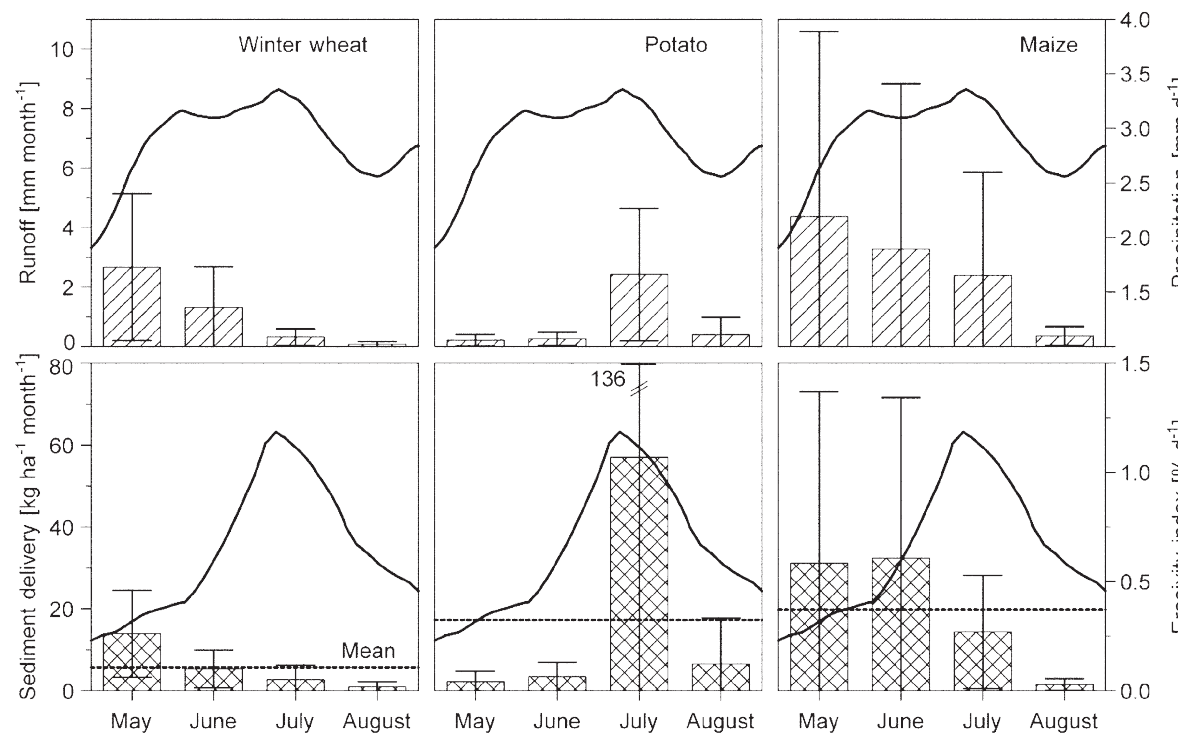

Fig. 2. Runoff (top) and sediment delivery (bottom) during the vegetation period from watersheds where winter wheat, potato, and maize were cultivated. Results are arithmetic means to allow a comparison with results from other studies, although $95 \%$ confidence intervals (error bars) below zero indicate that the measurements were not normally distributed. Lines show precipitation (top) and erosivity index (bottom). All data were averaged for 1994 to 2001 with 16 watershed years for winter wheat and eight watershed years for maize and potato, and two meteorological stations for precipitation properties.

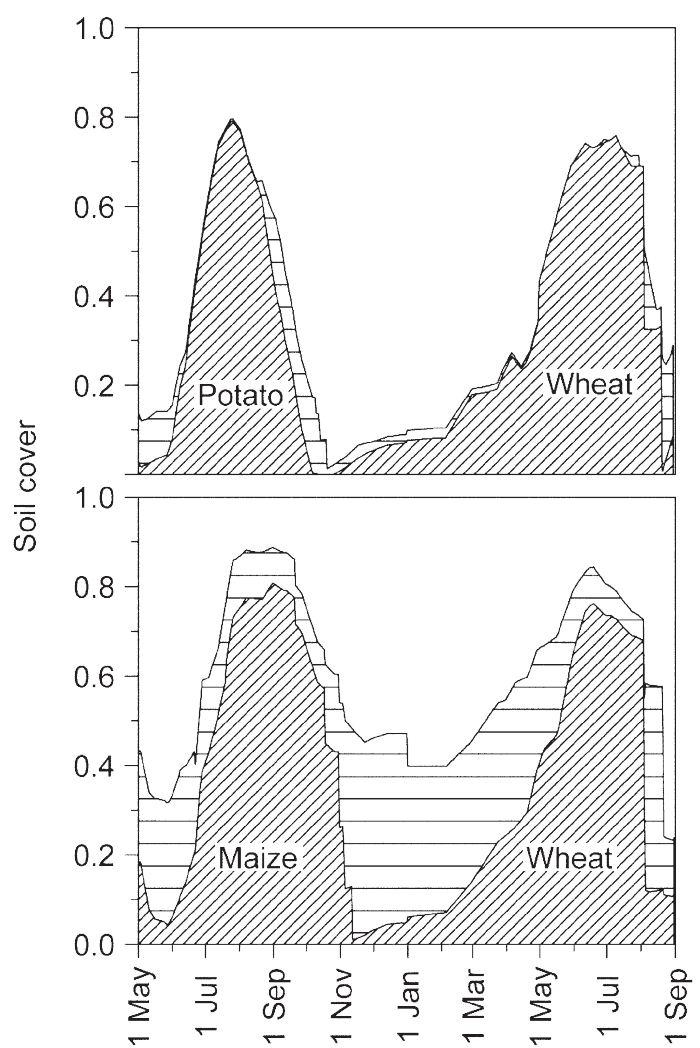

Fig. 3. Total soil cover measured at nine fixed positions distributed across the tested watersheds during 4 yr for the potatowheat and the maize-wheat sequences. Diagonal hatched area denotes plant cover, horizontally hatched area denotes the amount of residue cover contributing to total soil cover. with winter wheat cultivation, while 2.09 and 1.69 events per month occurred during the eight watershed years of potato and maize cultivation, respectively. The monthly average runoff during the vegetation period for winter wheat, potato, and maize was $1.10,0.82$, and $2.60 \mathrm{~mm}$, respectively (Fig. 2). In the case of winter wheat and maize, the runoff per month decreased from May to August, whereas the monthly rain amount increased from May to July. For potato, the highest runoff volumes were observed in July, while runoff was always $<0.4 \mathrm{~mm} \mathrm{mo}^{-1}$ for all other months. The large confidence intervals, especially in the case of maize, indicate that runoff from the small watersheds was highly variable among years because of a year-to-year variability in plant growth and storm size distribution, and possibly due to interactions with watershed characteristics.

Remarkably, the highest sediment delivery ( $57 \mathrm{~kg} \mathrm{ha}^{-1} \mathrm{mo}^{-1}$ ) matched with the month of the highest erosivity index only for potato because potato reached $80 \%$ soil cover only for a short period of time in contrast to the two other crops (Fig. 3). The monthly average sediment delivery during the vegetation period for winter wheat, potato, and maize was 5.7, 17.3, and $19.8 \mathrm{~kg} \mathrm{ha}^{-1}$, respectively (Fig. 2). Comparing winter wheat and potato, a similar runoff amount led to a more than threefold higher sediment delivery in the case of potato. Nevertheless, except for Watershed W1, maize produced slightly more sediment delivery than potato. This agreed with different CP factors for the four watersheds. While the $\mathrm{P}$ factor in potato was lower due to the effect of the ridges, the $\mathrm{C}$ factor was higher because the residues of the preceding cover crop were partly destroyed when planting and ridging potato and because the potato crop established slowly (Fig. 4). This resulted in a similar combined CP factor for maize and potato as long as potato was grown along the contour. The protection by ridges was not effective in Watershed W1 due to the field layout. The predicted combined CP factor for this watershed, therefore, is about five times higher for potato than for maize (Fig. 4). This also agreed well with the measured soil deliveries from this watershed, which were about four times higher for potato $(224 \mathrm{~kg}$ $\mathrm{ha}^{-1} \mathrm{yr}^{-1}$ ) than for maize $\left(56 \mathrm{~kg} \mathrm{ha}^{-1} \mathrm{yr}^{-1}\right)$, although both values are based on only 2 yr. We may conclude that the direct effects exerted by the crops due to differences in cover and surface roughness are well predicted by the $\mathrm{C}$ and $\mathrm{P}$ factors. The direct effects of both crops mainly acted via soil cover and ridge roughness.

\section{Carryover Effects}

While during the vegetation period the differences between potato and maize were small even when all watersheds were combined (17.3 vs. $19.8 \mathrm{~kg} \mathrm{ha}^{-1} \mathrm{mo}^{-1}$; Fig. 2), the picture changed when the following wheat crop was also considered (Fig. 5). The 


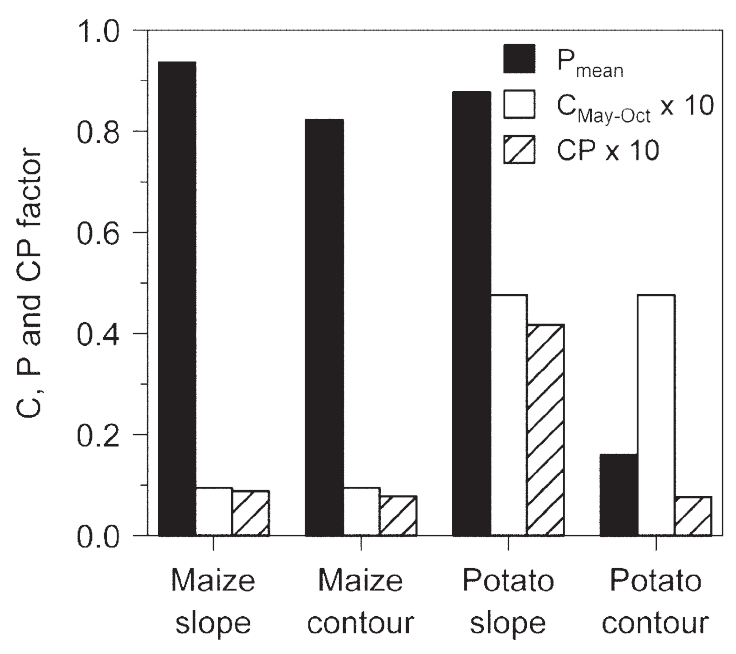

Fig. 4. Average cover-management factor $C$ and support practice factor $\mathbf{P}$ of the Revised Universal Soil Loss Equation (Renard et al., 1996; Auerswald et al., 2006). The $C$ and $P$ factors were calculated separately for Watershed $\mathrm{W} 1$, where ridges followed the slope (maize slope or potato slope), and Watersheds W2 to W4, where ridges followed contours (maize contour or potato contour).

soil loss of the potato-winter wheat sequence $\left(41.4 \mathrm{~kg} \mathrm{ha}^{-1} \mathrm{mo}^{-1}\right)$ was more than twice that of the maize-winter wheat sequence $\left(19.0 \mathrm{~kg} \mathrm{ha}^{-1} \mathrm{mo}^{-1}\right)$. The difference was especially large during the first months after the preceding crop, when the protection by the wheat crop itself was missing or small (ratio between potato-winter wheat and maize-winter wheat sequence of 3.9 for the average sediment delivery of November and December) but it was still detectable under full-grown wheat (ratio of 2.1 for the average between May and August). Especially in years with a large erosive event shortly after potato harvest and wheat sowing, large soil losses were measured.

Three main reasons for the differences in soil loss between winter wheat after potato and after maize were identified: (i) soil protection from rain impact by plant and plant residue cover, (ii) hydraulic roughness influenced by aggregate and residue roughness, and (iii) aggregate stability.

The potato harvest decreased the residue cover, on average, to about 2\% (1993-1996). In contrast, about 45\% of cover was left, on average, after maize harvest (Fig. 3). Therefore, the soil was less protected from raindrop impact and, moreover, hydraulic roughness caused by residues was reduced and hence it must be assumed that the surface runoff velocity was larger (e.g., Gilley et al., 1986) after potato, increasing detachment and transport capacity.

Additionally, sieving the soil for the potato harvest caused a mechanical disintegration of large aggregates and a weakening of small aggregates. The median aggregate diameter was considerably smaller after the potato harvest than before harvest or compared with the maize field (Fig. 6), although in both cases field operations after the row crop harvest were identical (chisel plowing, sowing of winter wheat). Thus, the roughness caused by soil aggregates was decreased and the aggregate transportability was increased due to the potato harvest.

The difference in soil roughness, indicated by the different amount of residue and different aggregate size, was also evident from the roughness measurements. The average RFR under win-

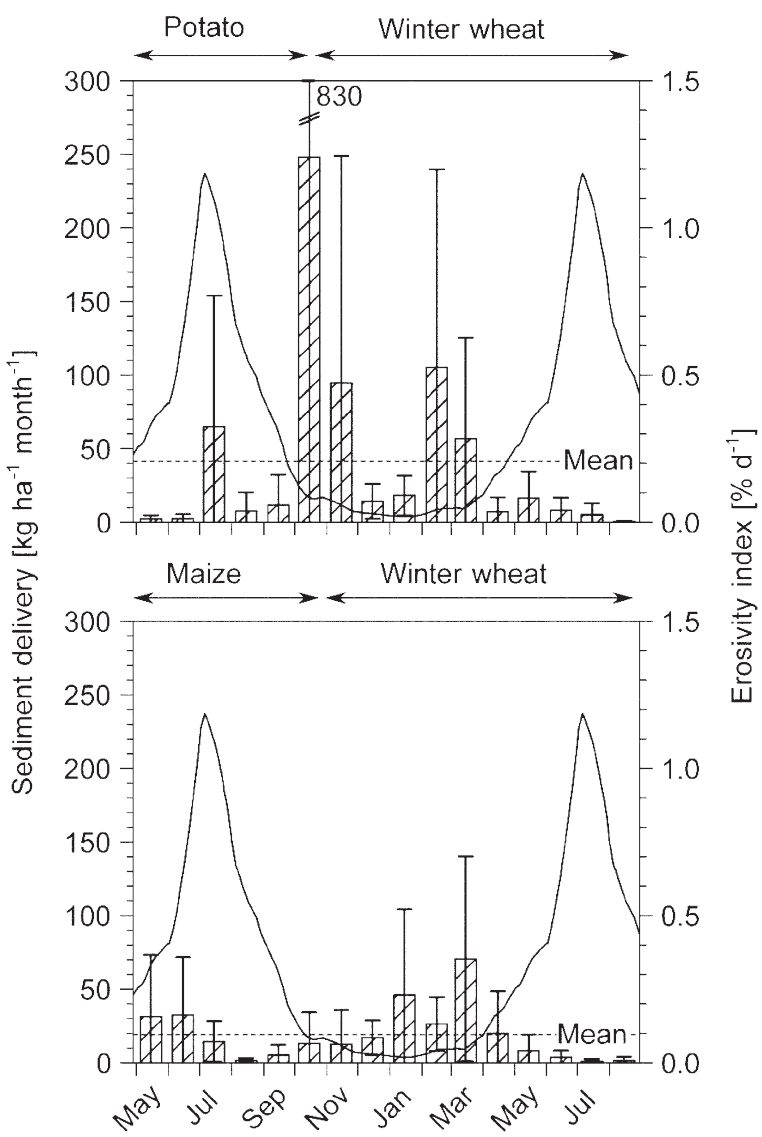

Fig. 5. Monthly average sediment delivery (bars) between 1994 and 2001 for the potato-winter wheat $(n=7)$ and maize-winter wheat sequences $(n=8)$, and corresponding erosivity indexes (lines). Error bars indicate the $95 \%$ confidence intervals. Results are arithmetic means to allow a comparison with results from other studies, although $95 \%$ confidence intervals (error bars) below zero indicate that the measurements were not normally distributed.

ter wheat after potato $(\mathrm{RFR}=18.6, \mathrm{SD}=3.8, n=74)$ was significantly $(P<0.01)$ smaller then the RFR measured under winter wheat after maize $(\mathrm{RFR}=21.8, \mathrm{SD}=4.2, n=41)$. In both cases, no trend in RFR development between October 1994 and May 1995 could be found.

The weakening of the aggregates due to the mechanical strain during potato cultivation becomes obvious from the percolation stability test (Fig. 7). This strain already occurs during potato growth due to planting, ridging, and the raindrop impact on a surface, which is less protected by cover than under maize. The percolation stability was lower by a factor of four under potato compared with maize. The trafficking of the furrows with narrow tires reduced the percolation stability further compared with ridges $\left(0.41\right.$ and $0.60 \mathrm{~mL} \mathrm{~min}^{-1}$, respectively; with $n=6$ each and $P<0.05)$. Under wheat, the difference in aggregate stability between maize and potato was inherited, although a slight increase in stability following the row crop occurred in both cases.

In contrast to percolation stability, density of the 8- to 5$\mathrm{mm}$ aggregates remained unchanged. It varied between 1.52 and $1.93 \mathrm{~g} \mathrm{~cm}^{-3}$ and was 0.4 to $0.6 \mathrm{~g} \mathrm{~cm}^{-3}$ higher than the bulk density. Variation within a sample was larger than between samples. Also, the water drop penetration time was similar for all samples. 


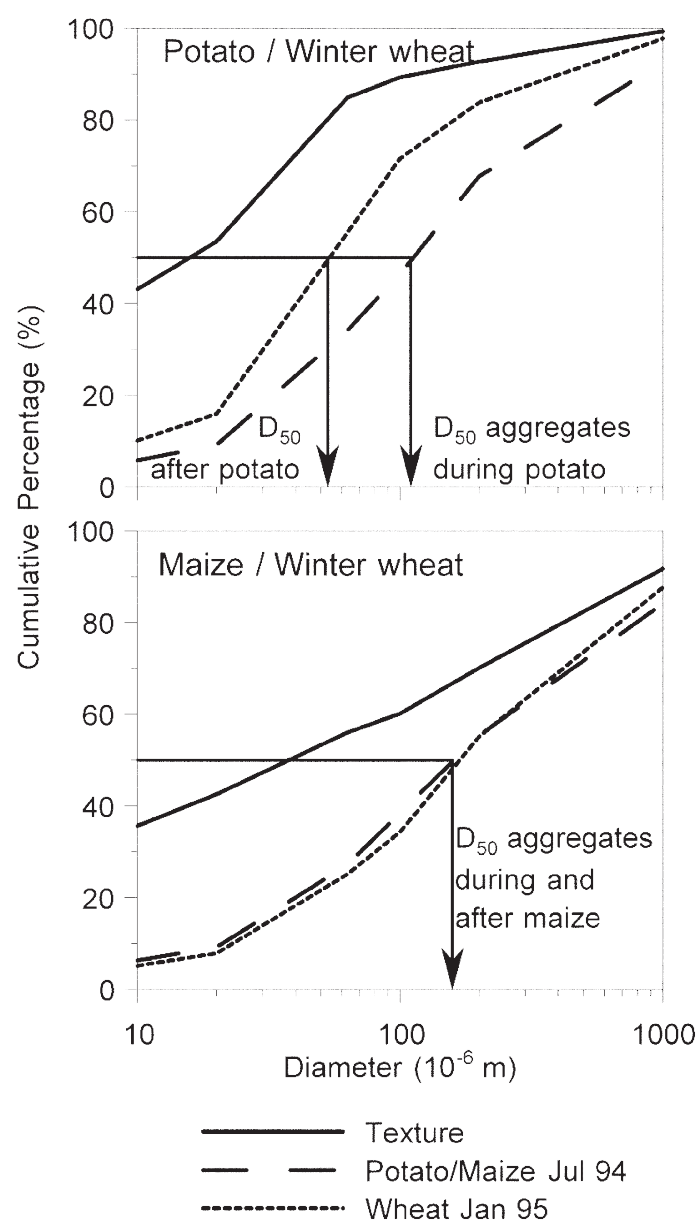

Fig. 6. Aggregate size of the topsoil $(0-3 \mathrm{~cm})$ sampled at two locations in July 1994 (during the row crop) and January 1995 (after row crop harvest and winter wheat establishment) for the maize-winter wheat (close to Watershed W1) and the potato-winter wheat sequences (in Watershed W3); $D_{50}$ is the median aggregate diameter.

In general, the suspected reasons for a carryover effect of potato to the following winter wheat crop were proven by measurements of soil properties and plant residue cover. This strengthens the notion that the measured difference in soil loss is not accidental due to the stochastic nature of erosion events but is the consequence of systematic differences in soil state after different crops. The carryover effect of potato to following small grain crops should be taken into account for soil conservation planning and the effects on soil properties should be taken into account for erosion modeling.

Even with the ridges oriented mainly perpendicular to the slope and with a mulched cropping system, potato remained an erosive crop because of its negative carryover effect on the following wheat crop, which did not profit from the ridge roughness or the mulch. In addition to its effect in promoting water erosion, potato also enhances tillage erosion (Kachanoski and Carter, 1999) and soil losses with harvested tubers (Ruysschaert et al., 2006; Auerswald et al., 2006) and thus must be regarded as one of the most erosive crops.

\section{CONCLUSIONS}

A mulch-planting potato system protects the surface less than mulched maize. When potato was planted along the contour, the

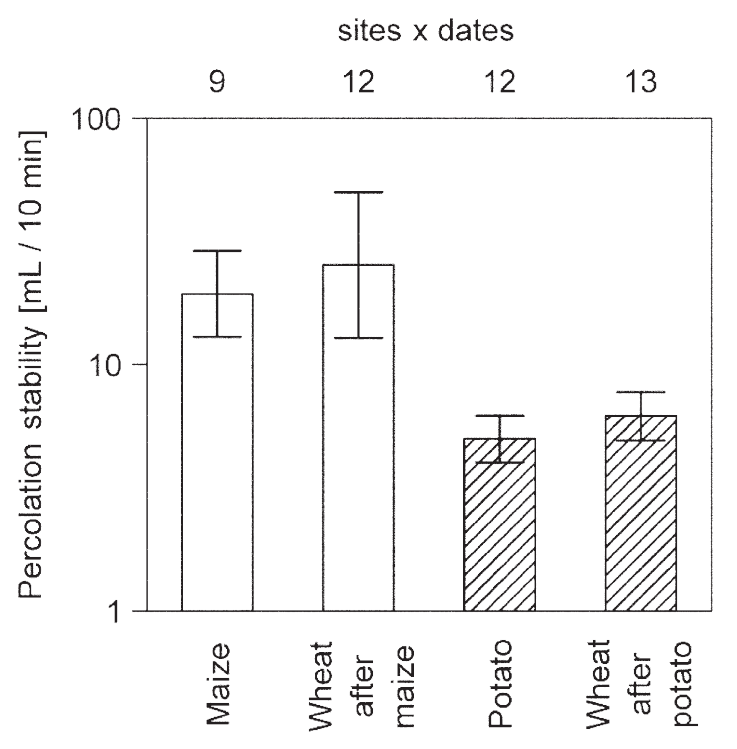

Fig. 7. Percolation stability measured at five different locations within the watersheds between 1993 and 1995. Error bars indicate the $95 \%$ confidence interval for the mean percolation stability.

reduced cover was compensated by the effect of the potato ridges due to runoff retention and deceleration, compared with more cover and less roughness under maize. Therefore, about the same soil loss was measured for maize and potato. The effects of cover and roughness on the soil loss could be well quantified by the $\mathrm{C}$ and P factors of the RUSLE.

Large differences in soil loss, however, occurred under the wheat crop following these row crops. Soil loss under wheat was about two times greater after potato than after maize. Less residue cover after potato, disintegration of large aggregates during the potato harvest, and a lower aggregate stability were detected and can explain this. Potato thus increases erosion more than maize but this is mainly caused by the adverse carryover effects and not directly during the year of potato cultivation.

This carryover effect should be taken into account when optimizing crop rotations with respect to soil conservation; for example, a crop with slow development of plant cover such as spring-sown crops should not follow a crop like potato. Moreover, it is highly relevant for the modeling of water erosion from agricultural areas.

\section{ACKNOWLEDGMENTS}

The scientific activities of the research network "Forschungsverbund Agrarökosysteme München" (FAM) were financially supported by the German Federal Ministry of Education and Research (BMBF 0339370). The Bavarian State Ministry for Science, Research and Arts funded overhead costs of the research station. We thank all members of the FAM project contributing to the manuscript with fruitful discussion or the collection of data sets used here, especially to Max Kainz, who stimulated the potato research in Scheyern and beyond.

\section{REFERENCES}

Auerswald, K. 1995. Percolation stability of aggregates from arable topsoils. Soil Sci. 159:142-148

Auerswald, K., H. Albrecht, M. Kainz, and J. Pfadenhauer. 2000. Principles of sustainable land-use systems developed and evaluated by the Munich Research Alliance on agro-ecosystems (FAM). Petermanns Geogr. Mitt. 144:16-25. 
Auerswald, K., G. Gerl, and M. Kainz. 2006. Influence of cropping system on harvest erosion under potato. Soil Tillage Res. 89:22-34.

Auerswald, K., and M. Kutilek. 1998. A European view to the protection of the soil resource. Soil Tillage Res. 46:9-11.

Becher, H.H., K. Muller, and E. Schneider. 1990. Determination of the bulkdensity of small single aggregates by submersed weighing following paraffining. Z. Pflanzenernaehr. Bodenkd. 153:369-371.

Bisdom, E.B.A., L.W. Dekker, and J.F.T. Schoute. 1993. Water repellency of sieve fractions from sandy soils and relationships with organic material and soil structure. Geoderma 56:105-118.

Ciesiolka, C.A.A., B. Yu, C.W. Rose, H. Ghadiri, D. Lang, and C. Rosewell. 2006. Improvement in soil loss estimation in USLE type experiments. J. Soil Water Conserv. 61:223-230.

Fiener, P., and K. Auerswald. 2003a. Concept and effects of a multi-purpose grassed waterway. Soil Use Manage. 19:65-72.

Fiener, P., and K. Auerswald. 2003b. Effectiveness of grassed waterways in reducing runoff and sediment delivery from agricultural watersheds. J Environ. Qual. 32:927-936.

Flacke, W., K. Auerswald, and L. Neufang. 1990. Combining a modified Universal Soil Loss Equation with a digital terrain model for computing high resolution maps of soil loss resulting from rain wash. Catena 17:383-397.

Foster, G.R. 2005. Draft science documentation: Revised Universal Soil Loss Equation Version 2 (RUSLE2). USDA-ARS, Washington, DC

Gilley, J.E., S.C. Finkner, R.G. Spomer, and L.N. Mielke. 1986. Runoff and erosion as affected by corn residue. Part I: Total losses. Trans. ASAE 29:157-160

Hill, R.D., and M.R. Peart. 1998. Land use, runoff, erosion and their control: A review for southern China. Hydrol. Proc. 12:2029-2042.

Jester, W., and A. Klik. 2005. Soil surface roughness measurement: Methods, applicability, and surface representation. Catena 64:174-192.

Kachanoski, R.G., and M.R. Carter. 1999. Landscape position and soil redistribution under three soil types and land use practices in Prince Edward Island. Soil Tillage Res. 51:211-217.

Kagerer, J., and K. Auerswald. 1997. Erosion prediction maps 1:5000 for land reconsolidation planning and agricultural advice. (In German, with English abstract.) Bodenkultur und Pflanzenbau 2/97. Bayerische Landesanstalt für Landwirtschaft, Munich.

Kainz, M. 1989. Runoff, erosion and sugar beet yields in conventional and mulched cultivation. Results of the 1988 experiment. p. 103-114. In U. Schwertmann et al. (ed.) Soil protection measures in Europe. Soil Technol. Ser. 1. Catena Verlag, Cremlingen, Germany.

Lal, R. 1998. Soil erosion research methods. Soil and Water Conserv. Soc., Ankeny, IA.

Mbagwu, J.S.C., and K. Auerswald. 1999. Relationship of percolation stability of soil aggregates to land use, selected properties, structural indices and simulated rainfall erosion. Soil Tillage Res. 50:197-206.

Morgan, R.P.C. 1996. Soil erosion and conservation. Addison-Wesley, Boston, MA. Morgan, R.P.C., J.N. Quinton, R.E. Smith, G. Govers, J.W.A. Poesen, K. Auerswald,
G. Chisci, D. Torri, and M.E. Styczen. 1998. The European soil erosion mode (EUROSEM): A dynamic approach for predicting sediment transport from fields and small catchments. Earth Surf. Processes Landforms 23:527-544.

Quinton, J.N., and J.A. Catt. 2004. The effects of minimal tillage and contour cultivation on surface runoff, soil loss and crop yield in the long-term Woburn Erosion Reference Experiment on sandy soil at Woburn, England. Soil Use Manage. 20:343-349.

Rasmussen, K.J. 1999. Impact of ploughless soil tillage on yield and soil quality: A Scandinavian review. Soil Tillage Res. 53:3-14.

Renard, K.G., G.R. Foster, G.A. Weesies, D.K. McCool, and D.C. Yoder 1996. Predicting soil erosion by water: A guide to conservation planning with the Revised Universal Soil Loss Equation (RUSLE). Agric. Handbk. 703. USDA-ARS, Washington, DC.

Ruysschaert, G., J. Poesen, G. Verstraeten, and G. Govers. 2006. Soil losses due to mechanized potato harvesting. Soil Tillage Res. 86:52-72.

Saleh, A. 1993. Soil roughness measurement: Chain method. J. Soil Water Conserv. 48:527-529.

Schröder, R., and K. Auerswald. 2000. Modelling the seasonal variation of silting induced runoff generation in small agricultural watersheds. (In German.) Z. Kulturtech. Landentw. 41:167-172.

Schwertmann, U., W. Vogl, and M. Kainz. 1987. Soil erosion by water: Prediction of soil loss and valuation of counter-measures. (In German.) Ulmer Verlag, Stuttgart, Germany.

Sinowski, W., and K. Auerswald. 1999. Using relief parameters in a discriminant analysis to stratify geological areas with different spatial variability of soil properties. Geoderma 89:113-128.

Warren, S.D., M.G. Hohmann, K. Auerswald, and H. Mitasova. 2004. An evaluation of methods to determine slope using digital elevation data. Catena 58:215-233.

Wischmeier, W.H. 1959. A rainfall erosion index for a universal soil-loss equation. Soil Sci. Soc. Am. Proc. 23:246-249.

Wischmeier, W.H. 1975. Estimating the soil loss equation's cover and management factor for undisturbed areas. p. 118-124. In Present and prospective technology for predicting sediment yields and sources: Proc. Sediment-Yield Worksh., Oxford, MS. 28-30 Nov. 1972. USDA Sedimentation Lab., Oxford, MS.

Wischmeier, W.H., and D.D. Smith. 1960. A universal soil-loss equation to guide conservation farm planning. p. 418-425. In Trans. Int. Congr. Soil Sci. Madison, WI. Vol. 7. Int. Soc. Soil Sci., Wageningen, the Netherlands.

Wischmeier, W.H., and D.D. Smith. 1978. Predicting rainfall erosion losses A guide to conservation planning. Agric. Handbk. 537. U.S. Gov. Print Office, Washington, DC

Yoder, D.C., J.P. Poster, J.M. Laflen, J.R. Simanton, K.G. Renard, D.K. McCool, and G.R. Foster. 1997. Cover-management factor (C). p. 143181. In K.G. Renard et al. (ed.) Predicting soil erosion by water: A guide to conservation planning with the Revised Universal Soil Loss Equation (RUSLE). Agric. Handbk. 703. USDA-ARS, Washington, DC. 